九州大学学術情報リポジトリ

Kyushu University Institutional Repository

Construction of Water Demand Prediction Model : Referring to the Thailand Gravity Irrigation District (4)

Fukuda, Tetsuro

Faculty of Agriculture, Gradute School, Kyushu University

https://doi.org/10.5109/4698

出版情報：九州大学大学院農学研究院紀要. 50 (2)，pp.899-907，2005-10-01. Faculty of Agriculture, Kyushu University

バージョン：

権利関係 : 


\title{
Construction of Water Demand Prediction Model -Referring to the Thailand gravity irrigation district (4)-
}

\author{
Tetsuro FUKUDA* \\ Laboratory of Irrigation and Water Utilization, Division of Regional Environment Science, \\ Department of Bioproduction Environmental Sciences, Faculty of Agriculture, \\ Graduate School, Kyushu University, Fukuoka 812-8581, Japan \\ (Received July 20, 2005 and accepted July 26, 2005)
}

\begin{abstract}
The planting area of various crops in the Sam Chuk district which was the Thailand gravity irrigation district was collected and was arranged, and the planting pattern was analyzed. As the result, the planting pattern was able to be expressed in the simple form of the trapezoid of the left-right symmetry. The parameter which formed the trapezoid in the every block was arranged. This would be able to quickly calculate planting area. In addition, the water demand prediction model for a series of work from the planting area calculation to a water demand calculation was made. The efficiency of a series of work was rapidly improved by this model construction.
\end{abstract}

\section{INTRODUCTION}

The planting area of various crops in the Sam Chuk district which was the Thailand gravity irrigation district was collected and was arranged, and the planting pattern was analyzed. As the result, the planting pattern was able to be expressed in the simple form of the trapezoid of the left-right symmetry. Then, the parameter which formed the trapezoid in the every block was arranged. A water demand can be quickly predicted, if this simplified planting pattern is utilized. The hardship that collects and arranges the data of the enormous planting area may not be done. In addition, the water demand prediction model for a series of work from the planting area calculation to a water demand calculation was made.

\section{CALCULATION OF PLANTING AREA}

\section{Modeling of planting pattern}

The planting data is based on the Village unit in Command area. The planting data must be arranged again in the regulator unit in order to calculate a water demand at the regulator unit.

Then, planting pattern of various crops is modeled trapezoidal of the left-right symmetry in dry season and rainy season. The time base is the week which makes January 1 $\sim 7$ to be the first week. The unit of the area is rai, and it is $1 \mathrm{rai}=1600 \mathrm{~m}^{2}$. Actually, the pattern is easy, if we work, while the graph is displayed by spread sheet software such as Excel. The example is shown in Fig. 1.

\footnotetext{
* Corresponding author (E-mail: tfukuda@bpes.kyushu-u.ac.jp)
} 


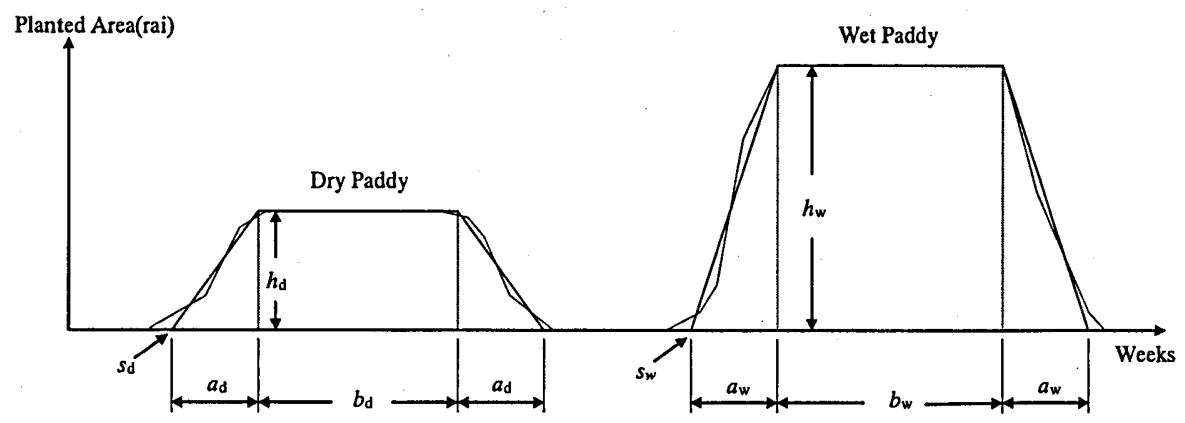

Fig. 1. Method of modeling of planting pattern $\mathrm{s}$ : Planting commencing time (unit : Weeks)

$\mathrm{a}:$ Increase or decrease period (unit: Weeks)

$\mathrm{b}:$ Peak duration (unit : Weeks)

$\mathrm{h}$ : Planting area (unit : rai). 1 rai $=1600 \mathrm{~m}^{2}$

Table 1.

\begin{tabular}{c|c}
\hline Range of $\mathrm{w}$ & Planting area \\
\hline $1 \leqq \mathrm{w} \leqq s$ & 0 \\
$s<\mathrm{w} \leqq s+a$ & $h^{*}(w-s) / a$ \\
$s+a<\mathrm{w} \leqq s+a+b$ & $h$ \\
$s+a+b<\mathrm{w} \leqq s+a+b+a$ & $h-h^{*}(w-s-a-b) / a$ \\
$s+a+b+a<\mathrm{w} \leqq 53$ & 0 \\
\hline
\end{tabular}

On the paddy rice, there is a case in which the planting pattern arises during dry season and rainy season, and this is similarly handled as a middle crop.

We can easily calculate the planting area from $s, a, b, h$ using equations in Table 1 , if we can decide parameters $s, a, b, h$ of planting pattern.

The planting pattern of sugarcane, fruits and fish ponds is made to be one year constant value.

By minutely examining the 1990 1992 data which we collected, we decided the planting pattern parameters. However, it was clarified that these gathered data sufficiently did not reflect present state. Especially, it is in the dry season paddy rice. Then, the data of each block for 3 years was compared and was examined, and the deducing was changed from the water supply results, the parameter of the planting pattern was corrected. In the analysis in the since then, this corrected planting pattern shall be used. Example of planting pattern parameter made in this way is shown in Table 2. This is the text file output of the data made in Excel, and this data file becomes input file of the planting area calculation program.

In the data file, only the data of each branch canal command block and main canal command block is made, and the data of the whole district is not being made. For exam- 
Table 2. Example of planting pattern (Section 1, File Name: CPTN1R90. prn)

\begin{tabular}{|c|c|c|c|c|c|c|c|c|c|c|c|c|c|}
\hline \multirow{2}{*}{\multicolumn{2}{|c|}{$\begin{array}{l}1990 \quad \text { Dry Paddy } \\
\text { Regurator s a b } \quad \text { h }\end{array}$}} & \multicolumn{2}{|c|}{ Mid Paddy } & \multicolumn{2}{|c|}{ Wet Paddy } & \multicolumn{2}{|c|}{ Dry Upland } & \multicolumn{3}{|c|}{ Wet Upland } & \multirow{2}{*}{$\begin{array}{l}\text { Sugar- } \\
\text { cane }\end{array}$} & \multicolumn{2}{|r|}{ Fish- } \\
\hline & & $\mathrm{s} a \mathrm{~b}$ & $\mathrm{~h}$ & $s \mathrm{a} \quad \mathrm{b}$ & $\mathrm{h}$ & $\mathrm{s} a \mathrm{~b}$ & $\mathrm{~h}$ & s a & $\mathrm{b}$ & $\mathrm{h}$ & & Fruits & Ponds \\
\hline 1D1D & 15.104000 & 81 & 2000 & 6 & & & 256 & 00 & & & & 58 & \\
\hline & 85207000 & 214 & 3868 & 7612 & 11585 & $\begin{array}{lll}11 & 3\end{array}$ & 161 & & 23 & ? & 126 & 3 & \\
\hline 1) & -25102500 & 12211 & 9915 & 1 & 12632 & $\begin{array}{lll}11 & 1\end{array}$ & 713 & & 24 & 84 & 51 & 32 & \\
\hline SL1 & 141 & 174 & 10000 & 32413 & 19392 & 00 & & 00 & 0 & & 55 & 200 & 135 \\
\hline 10 & 2675 & 174 & 5900 & 29710 & 12796 & $\begin{array}{lll}0 & 0 & 0\end{array}$ & 0 & 00 & 0 & 0 & 00 & 120 & \\
\hline RO & -85209000 & 9314 & 10266 & $278 \quad 9$ & 19133 & -7214 & 485 & 281 & 16 & 106 & 507 & 160 & 5 \\
\hline
\end{tabular}

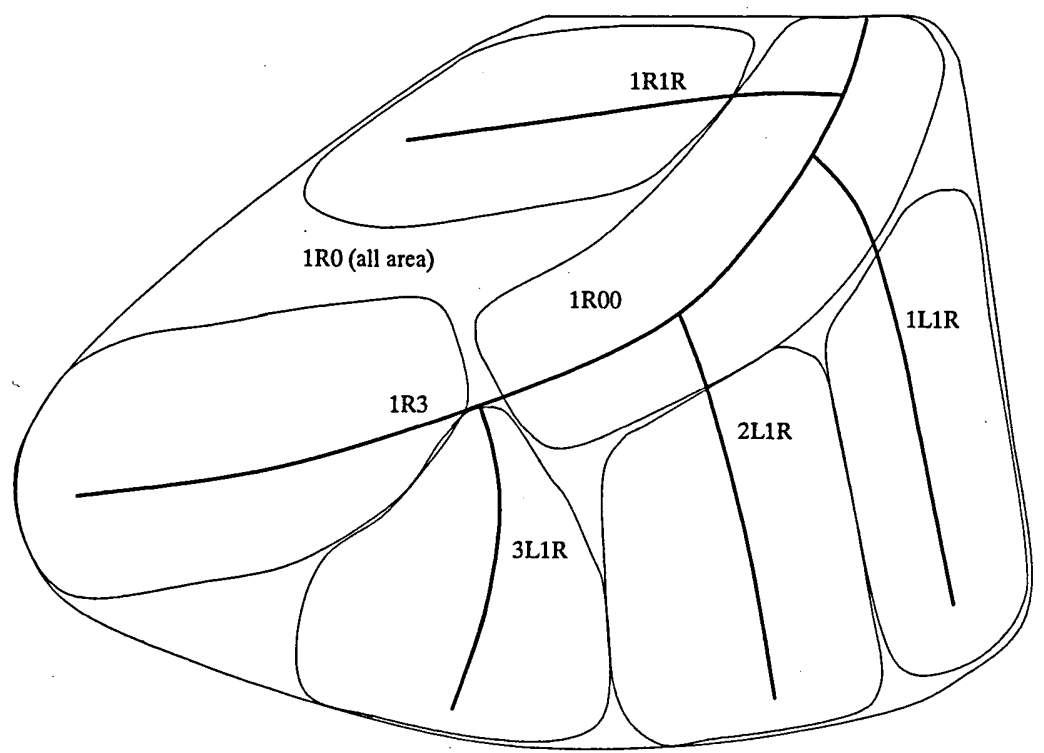

Fig. 2. Example of partition of command area (Section 1)

ple, the section 1 is composed of the blocks partitioned like Fig. 2. The planting area of the whole district (block 1R0 in the example of Fig. 2) is automatically calculated by the program of under-mentioned as a sum of planting area of the each partition block.

\section{Calculation of the planting area}

Planting pattern parameters made in the every block of Fig. 2 are developed by equations in Table 1, and the planting area is calculated. The operation panel of the water demand prediction program is shown in Fig. 3. For the calculation of the planting area, it is executed by clicking "Planting Pattern" button of the upper right of this panel. It is necessary to designate the planting pattern parameter file, before it is executed. By the 


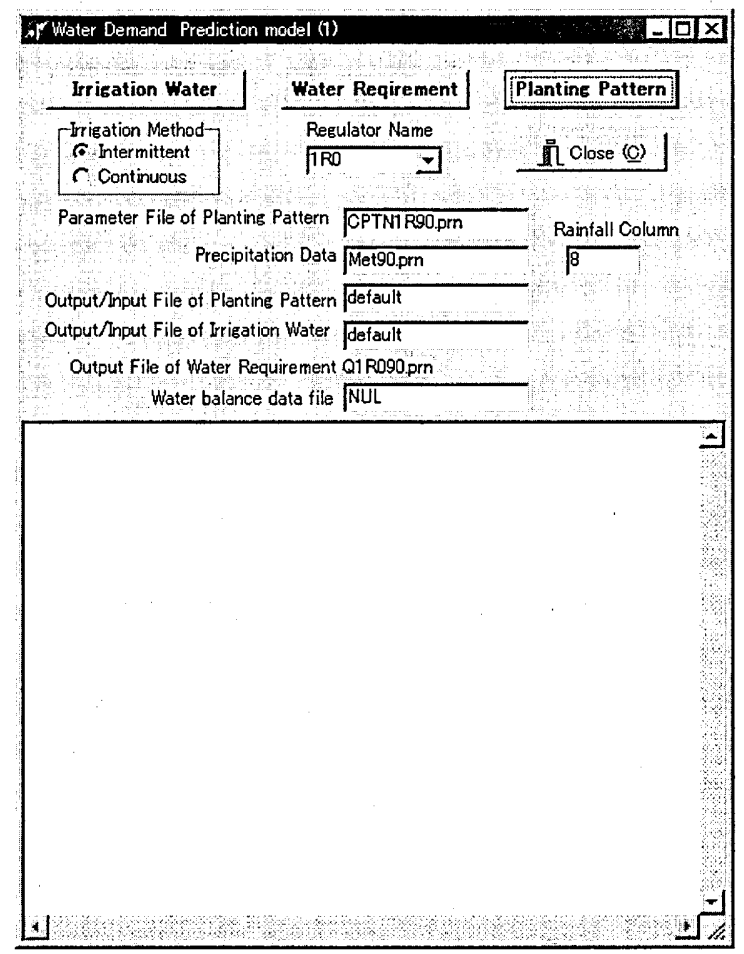

Fig. 3. Operation panel of water demand estimation program

execution of this program, planting area file of the every block is made. In this program, the planting area of each block is totaled, and in addition, planting area file of the whole section (block 1R0 of Fig. 2) is also output. In this case, the main canal command block is finally placed for input data files, and it is made to be block name (e.g. 1R00) which added 0 in entrance site regulator name (e.g. 1R0) (refer to Tabel 2). By deleting one 0 from the final block name by the program, if it is so done, the name of the whole district is made. Next 7 files are made by this operation in case of this example. Output file name and the number are different by the content of the input file. The contents of these files are displayed in the window under the operation panel of Fig. 3.

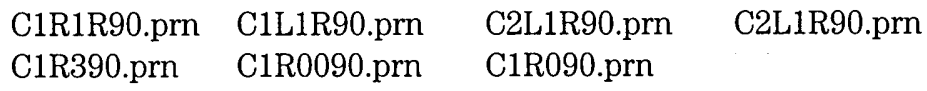

\section{CALCULATION OF IRRIGATION WATER REQUIREMENT}

The calculation of irrigation water requirement of the every crop clicks the "Irrigation Water" button of the upper left of the operation panel of above-mentioned Fig. 3. In this 
program, rainfall data are required. In Fig. 3, "Met90.prn" has been designated in the default. Rainfall data file is content in which the daily rainfall data ranged after 2 lines in a year, with the A.D. year (1990 in this case) in the head line. In the rainfall data file, other meteorological data may be included for other column. Column number of rainfall data is designated in the file name right, when other meteorological data are included. In the example, 8 is input. When there are rainfall data for the first column, 1 is designated.

Water balance data file is the file which outputs irrigation water, soil moisture, effective rainfall in every day, etc. The file name is input, when it is output for the file. It is input like the example with "NUL", when it is not output for the file. You should add the year in the file name like the example, when you designate "Irrigation water file", in order to distinguish from the file in other year. Alternatives "Intermittent or Continuous" under the execution button chooses the irrigation system. Generally, since intermittent irrigation is carried out, "Intermittent" is chosen. In this case, irrigation interval is calculated in 7 days. Though the result is output for the file, it is also displayed in the window under the panel.

\section{PREDICTION OF WATER REQUIREMENT}

In paddy fields, some percolated water returns to irrigation canal or the dual -purpose canals and is reused for irrigation. We assume the amount of reused irrigation water and predict the water requirement considering this reuse mechanism. Paddy field percolation is explained as follows.

(Paddy field percolation $)=($ Water requirement rate $)-($ Evapotranspiration $)$

$($ Evapotranspiration $)=($ Pan evaporation $) \times($ Pan coefficient $)$

Water requirement rate is consumptive water use in paddy field, and it is the sum of paddy field percolation and evapotranspiration. This is $11 \mathrm{~mm} / \mathrm{d}$ all year around based on the results of the field observation in the Sam Chuk Project (T. Fukuda, 2005).

Pan evaporation is used the value calculated by the Penman method. There is no problem using the mean value in a few years, because the year fluctuation is comparatively small for evaporation in this area, and because they are mean value $\pm 1 \mathrm{~mm} / \mathrm{d}$ in dry season, and because they are about mean value $\pm 2.5 \mathrm{~m} / \mathrm{d}$ in rainy season. Table 3 shows the average weekly values from 1983 to 1992 .

We can use RID data for pan coefficients (RID, 1990). These have been given in each growing season(weeks) as shown in Table 4. Generally, since 30-40 days are needed for the puddling in Thailand, the planting season is different of largest 5-6 weeks. Then, we got new pan coefficients by shifting, accumulating and averaging the original one for 5 weeks. Table 5 shows pan coefficients decided after considering this fact.

We call the water which outflows into an irrigation canal or the dual-purpose canal from paddy field "Return flow" and call the ratio "Return flow ratio". The following are considered at return flow : percolation, seepage and surface runoff, etc.. In this area, surface runoff is rare, and seepage is contained for percolation, it is considered, and return flow is defined in the following equation.

Namely,

(Return flow $)=($ Paddy field percolation $) \times($ Return flow ratio $)$

For return flow we call the amount of water which is reused "Reused water" and call 
Table 3. Potential evaporation by Penman method

\begin{tabular}{|c|c|c|c|c|c|c|c|c|c|c|c|}
\hline weeks & 1 & 2 & 3 & 4 & 5 & 6 & 7 & 8 & 9 & 10 & 11 \\
\hline $\mathrm{ET}_{n}$ & 4.2 & 4.2 & 4.4 & 4.5 & 4.7 & 5.1 & 5.3 & 5.5 & 5.9 & 6.1 & 6.4 \\
\hline weeks & 12 & 13 & 14 & 15 & 16 & 17 & 18 & 19 & 20 & 21 & 22 \\
\hline $\mathrm{ET}_{0}$ & 6.7 & 6.9 & 6.9 & 6.9 & 6.9 & 6.7 & 6.6 & 6.6 & 6.4 & 6.1 & 5.9 \\
\hline weeks & 23 & 24 & 25 & 26 & 27 & 28 & 29 & 30 & 31 & 32 & 33 \\
\hline $\mathrm{ET}_{0}$ & 5.7 & 5.4 & 5.3 & 5.4 & 5.4 & 5.4 & 5.4 & 5.4 & 5.2 & 5.1 & 5 \\
\hline weeks & 34 & 35 & 36 & 37 & 38 & 39 & 40 & 41 & 42 & 43 & 44 \\
\hline $\mathrm{ET}_{0}$ & 5 & 5 & 5 & 5 & 4.9 & 4.8 & 4.6 & 4.6 & 4.6 & 4.7 & 4.7 \\
\hline weeks & 45 & $\frac{}{46}$ & 47 & 48 & 49 & 50 & 51 & 52 & 53 & & \\
\hline $\mathrm{ET}_{0}$ & 4.6 & 4.6 & 4.4 & 4.5 & 4.4 & 4.3 & 4.3 & 4.2 & 4.2 & & \\
\hline
\end{tabular}

Table 4. Pan coefficient of growing season (rice paddy)

(After Crop coefficient and Pan coefficient (RID, 1990))

\begin{tabular}{cccccccccccccc}
\hline weeks & 1 & 2 & 3 & 4 & 5 & 6 & 7 & 8 & 9 & 10 & 11 & 12 & 13 \\
\hline ET/E & 1.04 & 1.07 & 1.14 & 1.25 & 1.42 & 1.54 & 1.55 & 1.55 & 1.49 & 1.37 & 1.23 & 1.12 & 1.06 \\
\hline
\end{tabular}

Table 5. Modified Pan coefficient of growing season (rice paddy)

\begin{tabular}{cccccccccc}
\hline weeks & 1 & 2 & 3 & 4 & 5 & 6 & 7 & 8 & 9 \\
\hline $\mathrm{ET} / \mathrm{E}$ & 1.04 & 1.05 & 1.08 & 1.12 & 1.18 & 1.24 & 1.32 & 1.40 & 1.46 \\
\hline & & & & & & & & & \\
\hline weeks & 10 & 11 & 12 & 13 & 14 & 15 & 16 & 17 & 18 \\
\hline $\mathrm{ET} / \mathrm{E}$ & 1.48 & 1.45 & 1.38 & 1.30 & 1.25 & 1.19 & 1.13 & 1.09 & 1.06 \\
\hline
\end{tabular}

the ratio "Return flow using ratio".

Namely,

$$
\begin{aligned}
(\text { Reused water })= & (\text { Return flow }) \times(\text { Return flow using ratio }) \\
= & (\text { Paddy field percolation }) \times(\text { Return flow ratio }) \\
& \times(\text { Return flow using ratio })
\end{aligned}
$$

If we define that (Reused water ratio) $=($ Return flow ratio $) \times($ Return flow using ratio), reused water can be explained as follows.

$($ Reused water $)=($ Paddy field percolation $) \times($ Reused water ratio $)$

Therefore, water requirement with regard to water reuse is as follows.

$($ Water requirement $)=($ Irrigation water - Reused water $) \times($ Planted area $)$

We predicted the reused water ratio based on the comparison of actual water supply and calculated water demand. The reused water ratio is as follows.

In the dry season (November to June) $\quad: 1.0$ 

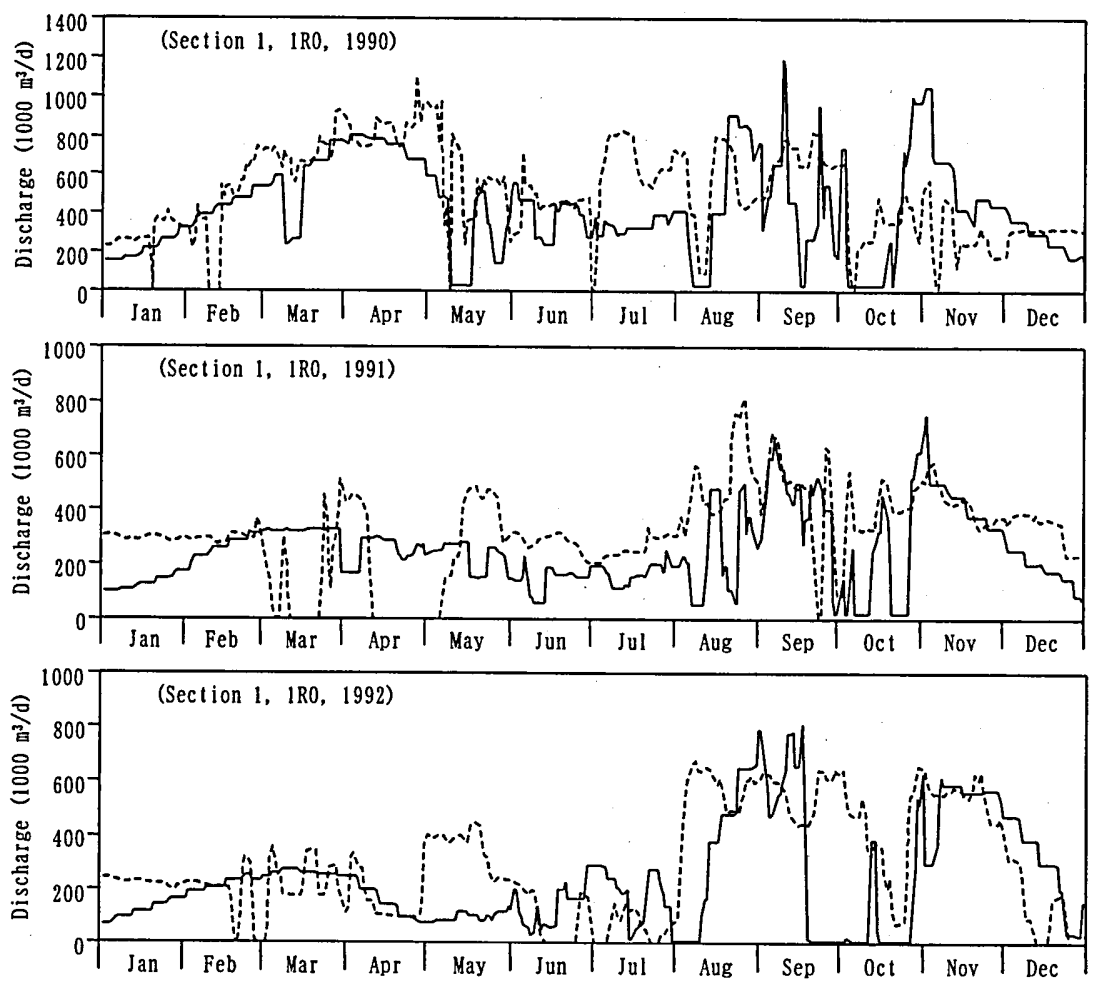

Fig. 4. Comparison between water demand by simulation and actual water supply (Section 1, 1R0, 1990-1992) (solid line : Actual water supply, broken line : Simulated water supply)

In the wet season (July to October)

The execution of the calculation may click the "Water Requirement" button of the upper center of the operation panel of Fig. 3. Calculating area prior to the execution, namely Regulator Name, is chosen. And, it is necessary to designate the file of irrigation water requirement already calculated. And, it is necessary to designate the file of irrigation water requirement already calculated. The output file is output of the file adequately named, if it is omitted. It is possible that the output file is graphed by reading in spread sheet software such as Excel. And, it is possible that we compare and examine actual values with the simulation value, if it is a regulator with the water intake record. The example is shown in Fig. 4.

\section{HOW TO USE THIS MODEL}

To begin with, anticipated planting pattern is made in the case of water demand prediction. Next, rainfall pattern is estimated, and irrigation water requirement is calculated. Finally, the prediction water requirement is calculated from prediction planting pattern 
and prediction irrigation water requirement.

\section{Anticipated planting pattern}

We have made the basic pattern by analyzing the planting pattern from 1990 to 1992. The prediction pattern preparation is carried out referring to these basic patterns. Since the basic patterns for paddy rice and field crops are trapezoids, parameters $s, a, b, h$ of the pattern shown in Fig. 1 may be estimated. And, planting area of sugarcane, fruits is predicted as a constant value all the year around.

By the click of "Planting Pattern" button of the operation panel of Fig. 3, it is possible to develop in planting pattern for a year, if the parameter of planting pattern of each crop is decided.

\section{Calculation of irrigation water requirement}

In the calculation of irrigation water requirement, it is required that the rainfall is predicted. We may choose rainfall pattern anticipated from these data, because we prepared rainfall data for ten years from 1983 to 1992.

Using rainfall data in chosen year, time series of irrigation water requirement is calculated by the click of "Irrigation Water" button of operation panel of Fig. 3.

\section{Calculation of prediction water requirement}

By the click of "Water Requirement" button of the operation panel of Fig. 3, it is possible to simply estimate water requirement, if prediction of the planting pattern and irrigation water requirement by the prediction rainfall are calculated.

\section{Application of this program}

When we predict the future planting pattern, we have been considering demand-oriented water control all the time. However, now supply-oriented water control can be used to decide the planting pattern. In this case, the prediction of the rainfall pattern is most important. In actual operation, there is no problem in the practical use, if it will be done as following.

It is difficult to predict the rainfall pattern for a whole year. If in advance we calculate several water requirement values based on several rainfalls patterns, we can select the most suitable one using our judgment.

In the water supply plan, planting pattern of three types may be assumed. There are years of a) abundant rainfall b) average rainfall c) insufficient rainfall. Then, there will be sufficiently, if the water supply in proportion to the rainfall of 3 types is grasped.

\section{CONCLUSION}

The convenient method for calculating the planting area was developed. By this, calculation and prediction of the planting area became also possible. A series of following work is necessary for the water requirement prediction. a) planting area prediction. b) calculation of irrigation water requirement. c) water requirement prediction. The program which carried out this a series of work continuously was developed. The efficiency of a series of work was rapidly improved by this program. And, this system became a pro- 
gram which indicated water demand prediction. I want to advance the research for water demand prediction in future.

\section{REFERENCES}

Royal Irrigation Department 1990 Crop Coefficient and Pan Coefficient (Thailand)

Testuro Fukuda 2005 Estimation model of water requirement in farmland-Referring to the Thailand gravity irrigation district (1)-, J. Fac. Agr., Kyushu Univ., 50(2) (in press)

Testuro Fukuda 2005 Actual Water Consumption and Water Management in Paddy Field-Referring to the Thailand gravity irrigation district (2)-, J. Fac. Agr., Kyushu Univ., 50(2) (in press)

Testuro Fukuda 2005 Estimation of Water Requirement for Each Area and Actual Water Allocation

-Referring to the Thailand gravity irrigation district (3)-, J. Fac. Agr., Kyushu Univ., 50(2) (in press) 